\title{
An Emerging Protagonist: Sodium Glucose Co-transporters (SGLTs) as a Burgeoning Target for the Treatment of Diabetes Mellitus
}

Danish Ahmed $^{1 *}$, Manju Sharma ${ }^{2}$, Vikas Kumar ${ }^{1}$ and Yadav Pankajkumar Subhashchandra ${ }^{1}$

${ }^{1}$ Department of Pharmaceutical Sciences, Sam Higginbottom Institute of Agriculture, Technology and Sciences (SHIATS)-Deemed University, India

${ }^{2}$ Department of Pharmacology, JamiaHamdard University, Hamdard Nagar, New Delhi, India

\begin{abstract}
Contemporary therapies to rationalize the hyperglycaemia in type 2 diabetes mellitus (T2DM) generally involve insulin-dependent mechanisms and lose their effectiveness as pancreatic b-cell function decreases to a greater extent. Kidney emerges out as a novel and potential target to trim down the complications of T2DM. The filtered glucose is reabsorbed principally through the sodium glucose co-transporter-2 (SGLT2), a low affinity transport system, which are present at the luminal surface cells that covers the first segment of proximal tubules. Competitive inhibition of SGLT2 therefore represents an innovative therapeutic strategy for the treatment of hyperglycaemia and/or obesity in patients with type 1 or type 2 diabetes by enhancing glucose and energy loss through the urine. Selective inhibitors of SGLT2 reduce glucose reabsorption, causing excess glucose to be eliminated in the urine; this decreases plasma glucose. SGLT2 inhibitors are coupled with osmotic dieresis and loss of weight which aid in reducing the blood pressure. The observation that individuals with familial renal glycosuria maintain normal longterm kidney function provides some encouragement that this mode of action will not adversely affect renal function. This novel mechanism of targeting kidney for the treatment of T2DM is reasonably valuable and is independent of insulin and clutch with the low risk of hypoglycemia.
\end{abstract}

Keywords: SGLT2; Diabetes; Kidney; Hyperglycemia; Type 2 diabetes mellitus

Abbreviations: SGLTs: Sodium-Dependent Glucose Cotransporters; T2DM: Type2 Diabetes Mellitus; HbA1c: Glycated Heamoglobin ; FPG: Fasting Plasma Glucose; HRQOL: Health Related Quality of Life; CFU: Colony Forming Units; OADs: Oral Antidiabetic Drugs

\section{Introduction}

Diabetes has become an engorgement apprehension worldwide. More or less 285 million people all over the world will be suffering from diabetes by the end of 2010. WHO estimates that more than 346 million people worldwide have diabetes [1]. This number is likely to become more than double by 2030 without intervention. Almost $80 \%$ of diabetes deaths occur in low- and middle-income countries. The most common disorder of glucose homeostasis is Type2 Diabetes Mellitus (T2DM). It accounts for $90-96 \%$ of all cases of diabetes [2]. SodiumDependent Glucose Cotransporters (SGLTs) facilitate the transport of glucose against a concentration gradient with synchronized transport of sodium down a concentration gradient [3]. The anticipation is that there is about $90 \%$ of total renal glucose reabsorption is aided by SGLT2. Thus a new therapeutic approach without dependence on insulin and appropriate for use in amalgamation with other agents would be preeminent choice for treatment of hyperglycemia in type 2 diabetes mellitus (T2DM). Sodium Glucose co-transporter inhibitors create a center of attention as there is a need of potential therapy for diabetes mellitus with lesser side effects $[4,5]$. This review scrutinize the niceties of various SGLT2 inhibitors

The role of SGLT is fundamental in the mutual transfer of sugar and sodium across the epithelial membrane. The transport of sugar takes place in the small intestine and the renal tubule through active transport. It necessitates the coupling of cellular energy metabolism to the transepithelial transfer. It is SGLT where the coupling takes place. There is no hydrolysis of ATP is engaged as compared to the primary active transport episodes for instance those intervened by ion translocating ATPases. As an alternative the SGLT exploit the energy accumulated in an ion gradient for the translocation of sugars against the concentration gradient. Sodium is the major ion present in the mammals whose gradient across the cell membrane has been used as thrust. The secondary active transport of sugars, carboxylic acid and the aminoacids rivet the synchronized movement of sodium ions by and large in the same direction as the substrate [6] (Figure 1).

Kidney is the main organ where active transport of sugar takes place in the early part of the proximal tubule. Research work on the transport of sugar in the early and late segments of proximal tubule and vesicles demonstrate that the kidney contains two D-glucose cotransporters with the difference in their stoichiometry for sodium in the early proximal tubule. There is a mutual translocation of one sugar and one sodium molecule in the luminal membrane while two sodium ions are transferred with one sugar molecule in the late part of proximal tubule. There is a divergence in the affinity for D-glucose for the two transporters [7] (Figure 2).

The transporter in the early part has been identified as SGLT1 at the same time the transporter found in the early proximal tubule as SGLT2.

The sodium gluocose co-transporter (SGLT2) is a high capacity, low affinity proximal tubular cell transporter that reabsorbs filtered glucose. Mutations in this transporter lead to renal glycosuria. In diabeticanimal models, there appears to be up-regulation of the SGLT2 receptors and

*Corresponding author: Danish Ahmed, Department of Pharmaceutical Sciences, Faculty of Health Sciences, Sam Higginbottom Institute of Agriculture, Technology and Sciences (SHIATS)-Deemed University, Allahabad, Uttar Pradesh, India Tel: 919580001578; Fax: 91532 2684190; E-mail: danish.ahmed@shiats.edu.in

Received February 24, 2014; Accepted March 16, 2014; Published March 22 2014

Citation: Ahmed D, Sharma M, Kumar V, Pankajkumar Y, chandra S (2014) An Emerging Protagonist: Sodium Glucose Co-transporters (SGLTs) as a Burgeoning Target for the Treatment of Diabetes Mellitus. J Diabetes Metab 5: 358 doi:10.4172/2155-6156.1000358

Copyright: (C) 2014 Ahmed D, et al. This is an open-access article distributed unde the terms of the Creative Commons Attribution License, which permits unrestricted use, distribution, and reproduction in any medium, provided the original author and source are credited. 


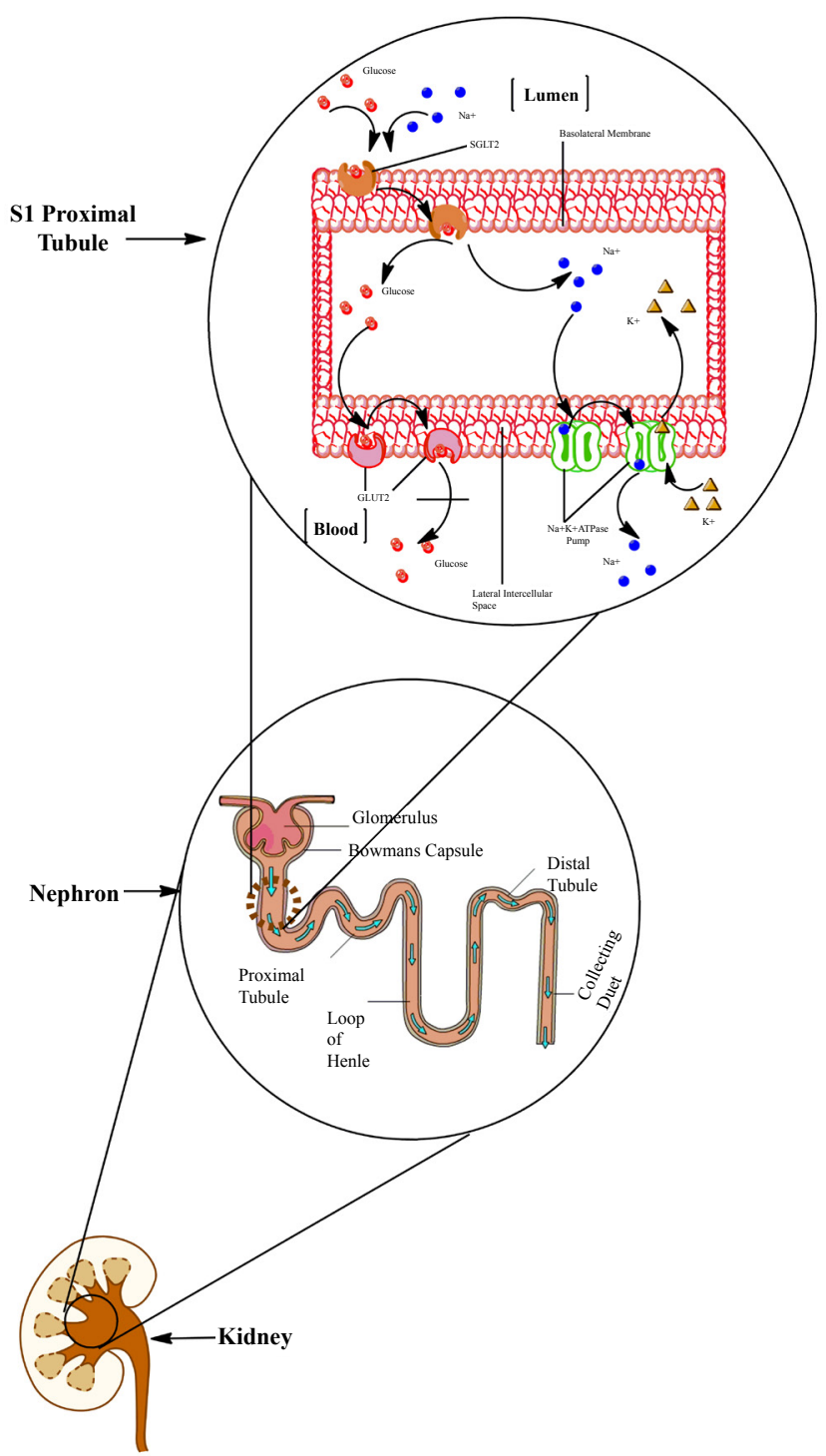

Figure 1: Reabsorption of glucose from the renal proximal tubules by the sodium glucose cotransporters SGLT2.

Almost all of the glucose entering glomeruli in the afferent glomerular arterioles is filtered into the nephron fluid of the proximal renal tubules. Most (up to $90 \%$ ) of this filtered glucose is reabsorbed in the initial proximal convoluted segment (S1) by SGLT2 located at the luminal surface of proximal tubular cells. Remaining glucose is reabsorbed from the filtrate in themore distal convoluted and straight segments by SGLT1. Glucose within the proximal tubular cells is then transported back to the interstitial compartment and thence to the plasma by the facilitative glucose transporters GLUT2 in the S1 segment, respectively. In normal individuals with an average plasma glucose concentration of 5-5.5 $\mathrm{mmol} / \mathrm{L}(90-100 \mathrm{mg} / \mathrm{dL})$, approximately $160-180 \mathrm{~g}$ of glucose is filtered daily, with less than $0.5 \mathrm{~g} /$ day of glucose appearing in the urine based on Bakris et al. and Bays.

GLUT2mRNA. SGLT2 antagonism provides an interesting therapeutic option to decrease glucose loads in diabetes. Nonspecific SGLT2 inhibitors like phlorizin have gastrointestinal side effects. More specific inhibitors like dapagliflozin and sergiflozin are being tested in small clinical trials. The effect on the progression of diabetic kidney disease remains to be studied [8].

\section{Sodium-D-Gluocse Transportation: Molecular Aspect}

Discovery of human intestinal SGLT1 by Ernie Wright and his acquaintances pave the way for the identification of an identical gene in the kidney [9]. This further allowed the researchers to do mutagenesis studies, structural elucidation and the discovery of substrate binding sites as well as inhibitor binding sites [8].

The extensive research on the membrane topology of the transporter which was possible only after the acquaintance of the sequence was done. The research showed that the $\mathrm{N}$-terminus of thee transporter is pointing outside of the cell with 14 transmembrane segments. The position of the loop 13-14 is essential after pholrizin binding site requires the loop 13-14. The C-terminus also plays a vital role in the recognition and translocation of the sugar [8]. The N-terminal segments IV-V are implicated in the recognition of sodium as well as glucose binding (Table 1).

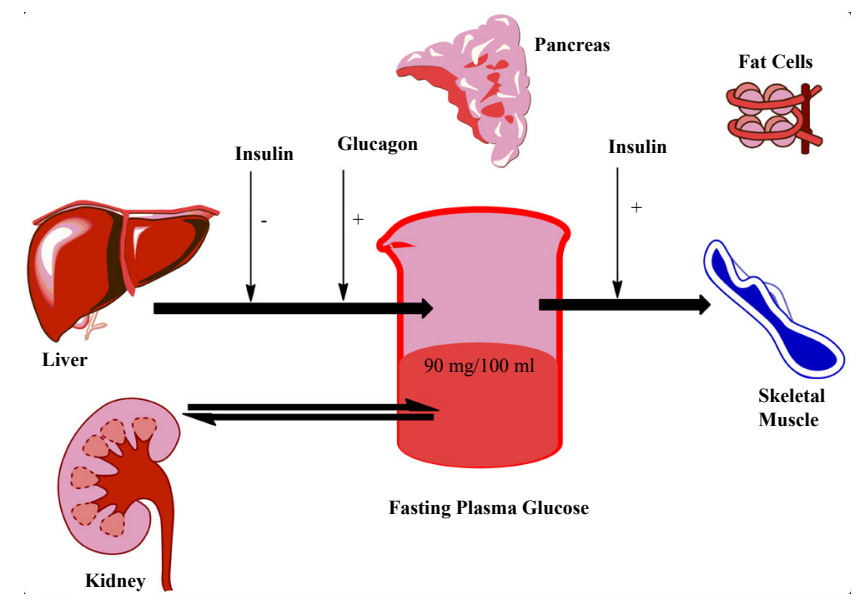

Figure 2: Normal glucose homeostasis.

This outlines the hormonal interactions that are important in regulating normal glucose homeostasis. Normal fasting glucose homeostasis involves the hormonal regulation of glucose utilization and production, as well as the filtration and reabsorption of glucose by the kidney10. Under basa conditions, glucose uptake by the tissues is matched by glucose production from the liver; this enables fine regulation of glucose at a fixed level. Gluconeogenesis in the liver helps prevent hypoglycaemia.

(Reproduced with permission from Edward C. Chao, Copyright @2010, Macmilan Publishers Limited).

\begin{tabular}{|c|c|c|c|}
\hline Compound & $\begin{array}{c}\text { Selectivity for } \\
\text { SGLT2 vs. SGLT1 } \\
\text { (Fold) }\end{array}$ & $\begin{array}{c}\text { UGE in humans at } \\
\text { highest dose; mean } \\
\text { value } \pm \text { SD } \text { (g/day) }\end{array}$ & $\begin{array}{c}\text { Reduction in } \\
\text { HbA1c (\%) }\end{array}$ \\
\hline ASP1941 & $255[28]$ & $\begin{array}{c}90.8 \pm 16.0[29] \\
58.9 \pm 14.6[31] \\
50[30]\end{array}$ & $-0.8[30]$ \\
\hline BI 10773 & $>2,500[32]$ & $\begin{array}{c}72.6 \pm 35.9[33] \\
88 \pm 20.3[34] \\
90.8[35]\end{array}$ & NR \\
\hline Canagliflozin & $414[36]$ & $\begin{array}{c}129.2 \pm 20.8 \mathrm{SE}[37] \\
113[38]\end{array}$ & $-0.92[37]$ \\
\hline Dapagliflozin & $1,200[39]$ & $70[22]$ & -0.61 to -0.89 \\
\hline LX4211 & $20[40]$ & $80[40]$ & $-1.25[40]$ \\
\hline
\end{tabular}

aSD unless otherwise indicated; SD/SE was not reported in some studies.

HbA1c: Hemoglobin A1c; NR: Not Reported; SD: Standard Deviation; SE: Standard Error; UGE: Urinary Glucose Excretion.

(Copyright 2011, American Society for Clinical Pharmacology and Therapeutics Adapted with permission from:

M Pfister et al. (2011) Inhibition of SGLT2: A Novel Strategy for Treatment of Type 2 Diabetes Mellitus, Clinical Pharmacology \& Therapeutics 89: 4)

Table 1: Pharmacodynamic parameters of SGLT2 inhibitors currently in development. 


\begin{tabular}{|c|c|c|}
\hline \multirow{2}{*}{ Sergliflozinetabonate } & \multicolumn{2}{|c|}{ Ki Value (nM) } \\
\hline Sergliflozin & $3350 \pm 110$ & Rat SGLT2 \\
\hline Phlorizin & $704 \pm 254$ & $651 \pm 149$ \\
\hline
\end{tabular}

Data are presented as means \pm S.E.M. from 3 experiments. An AMG uptake experiment was performed with COS-7 cells transiently transfected with rat SGLT1 or SGLT2, and the Ki values for each SGLT were calculated [20]

Table 2: Ki values of sergliflozinetabonate, sergliflozin, and phlorizin for rat SGLTs.

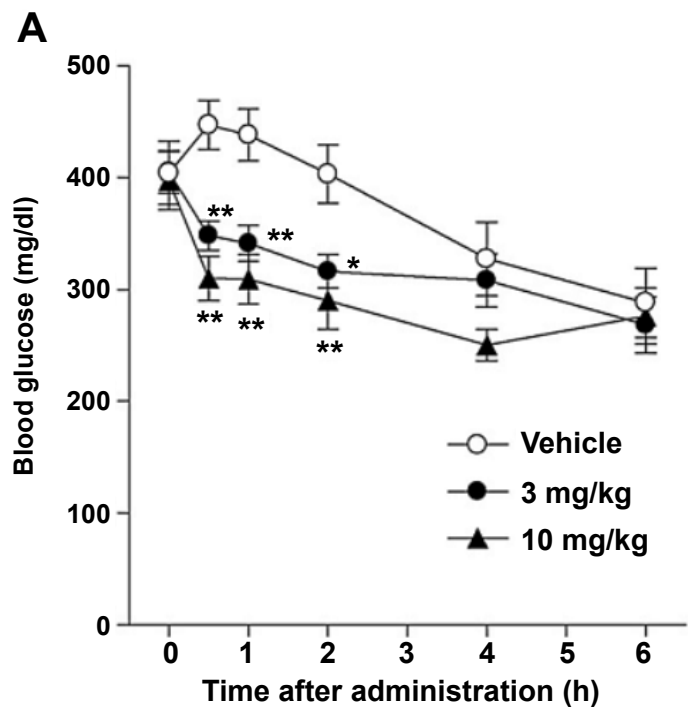

B

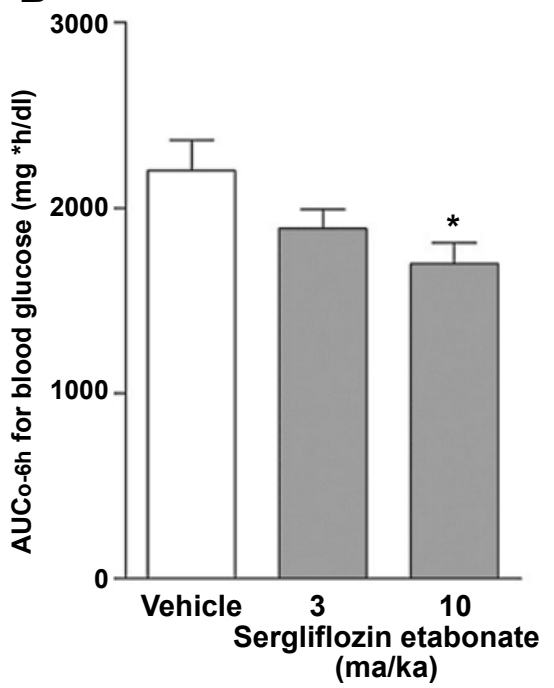

Figure 3: Acute effects of sergliflozinetabonate in Zucker fatty rats. Sergliflozinetabonate was orally administered to fed Zucker fatty rats. Blood glucose concentrations (A) were measured, and the AUCO-6 h for blood glucose $(B)$ was calculated. Data are presented as means \pm S.E.M. $(n=7-8)$. ${ }^{*} \mathrm{~Pb} 0.05,{ }^{*} \mathrm{~Pb} 0.01$ vs. vehicle group [20].

\section{SGLT: Binding Situate}

After exhaustive research it has been established that sugars in the hexose and D-configuration are transferred while sugars with L-configuration are unable to be transferred. The hydroxyl group at $\mathrm{C} 2$ position must be present in the equilateral manner in order to transport the sugars. Consequently the presence of hydroxyl group at
C3 position is also plays a vital role. The hydroxyl group at C6 is of not much importance. SGLT2 have one hydrophobic binding site at C6 position therefore the alkyl residues present at C6 have higher affinity than SGLT1 [10].

\section{Novel SGLT2 Inhibitors}

\section{Phlorizin}

It is beta glucoside obtained from the bark of apple roots. Phlorizin normalized plasma glucose and corrected glucotoxicity induced decline in insulin sensitivity and pancreatic $\beta$-cell function in animal models of diabetes mellitus [11-13].

Phlorizin has proved useful as a physiological research tool and has been used in this capacity for more than 150 years. But there are several limitation of this SGLT inhibitor is that it is non-selective SGLT inhibitor, inhibiting both SGLT2 and SGLT1 inhibitor [14,15].

Another limitation of phlorizin is to embrace the poor oral bioavailability and susceptibility of O-linkage to be cleaved by the $\beta$-glucosidase in the gastrointestinal tract $[11,16]$. For this reason phlorizin has to be given by parenteral route in order to be effective. In order to improve the shortcomings of the phlorizin, another compounds or derivatives of phlorizin came into existences which are discussed later in the article.

\section{T-1095}

It is improved derivative of phlorizin that can be administered orally as prodrug [17]. T-1095 is another O-glucoside with greater metabolic firmness as compared to the phlorizin. Though it is a nonselective SGLT inhibitor [16-18]. It was discontinued in the Phase-II clinical trial [16].

\section{Sergiflozin etabonate}

Sergliflozin is highly specific inhibitor of SGLT2 in its glycated form [19]. Sergliflozin is found to be very potent and selective for rat SGLT2 with a selectivity ration of 41 . Based on Ki value (Table 2 ) the selectivity of sergliflozin towards human SGLT2 was also found to be far above the ground. Sergliflozin etabonate (Active form of Sergliflozin) encouraged excretion of glucose depending on blood glucose level. Upon chronic administration of sergliflozinetabonate to Zuker fatty rats there is no alteration in body weight $(622.6 \pm 12.4,614.7 \pm 23.2$, and $615.8 \pm 15.6 \mathrm{~g}$ for vehicle, $10 \mathrm{mg} / \mathrm{kg}$ and $30 \mathrm{mg} / \mathrm{kg}$ group respectively) as well as the food intake $(30.6 \pm 2.0,29.5 \pm 2.5$, and $32.1 \pm 1.3 \mathrm{~g}$ for vehicle $10 \mathrm{mg} /$ $\mathrm{kg}$ and $30 \mathrm{mg} / \mathrm{kg}$ group respectively) but it reduces both the glycated heamoglobin (Figures 3A,3B) and fasting plasma glucose (Figure 4) [20].

Sergliflozin was discontinued for various unfavorable effects such as non-desired pharmaceutical properties, non-selectivity and development of new SGLT2 inhibitors [21-23].

\section{Dapagliflozin}

Dapagliflizon is potent inhibitor of human SGLT2 and has $\mathrm{EC}_{50}$ of $1.1 \mathrm{nM}$ with 1200 fold selectivity for human SGLT2 over SGLT1 and contain C-glucoside in lieu of O-glycoside linkage which makes it $\beta$-glucosidase resistant [24]. It is under clinical trial. Earlier clinical trials showed the efficacy of dapagliflozin versus placebo in the patients of type 2 diabetes mellitus and metformin [25] and sulfonylurea glimepiride [26].

A randomized noninferiority clinical trial was conducted by Nauck et al. [27] of dapagliflozin versus gliplizide. The trial showed 
A

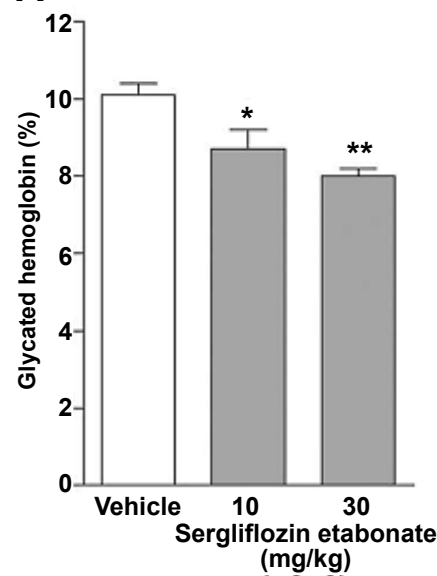

B

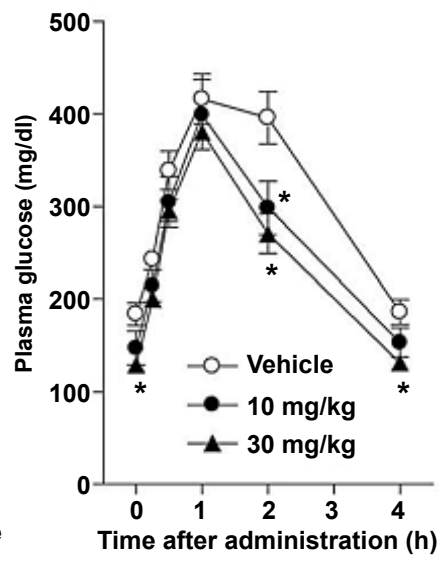

C

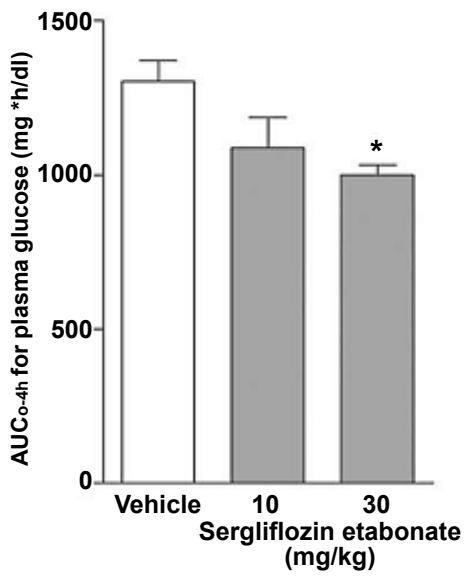

Figure 4: Chronic effects of sergliflozinetabonate in Zucker fatty rats.

Sergliflozinetabonate was orally administered to Zucker fatty rats twice daily for 2 weeks. At the end of the administration period, glycated hemoglobin (A) was determined; and the oral glucose tolerance test $(2 \mathrm{~g} / \mathrm{kg}$ ) was performed. Plasma glucose concentrations (B) were measured, and the AUC0-4 h for plasma glucose

(C) was calculated from the plasma glucose concentration during the oral glucose tolerance test. Data are presented as means $\pm \mathrm{S}$. $E . M$. $(\mathrm{n}=4-5)$. ${ }^{*} \mathrm{~Pb} 0.05$, ${ }^{* *} \mathrm{~Pb} 0.01$ vs. vehicle group [20].

\begin{tabular}{|c|c|c|c|c|c|c|c|c|c|c|c|c|c|}
\hline \multirow[t]{2}{*}{ Blood glucose Measure } & \multicolumn{6}{|c|}{$\begin{array}{l}\text { Dapagliflozin monotherapy in } 389 \text { treatment-naïve } \\
\text { patients in a } 12 \text {-week study }\end{array}$} & \multicolumn{4}{|c|}{$\begin{array}{l}\text { Dapagliflozin as an add-on to } \\
\text { metformin in } 546 \text { patients inadequately } \\
\text { controlled by metformin alone in a 24- } \\
\text { week study }\end{array}$} & \multicolumn{3}{|c|}{$\begin{array}{c}\text { Dapagliflozin combination } \\
\text { therapy in } 71 \text { patients inadequately } \\
\text { controlled by insulin plus OADs in a } \\
12 \text {-week study }\end{array}$} \\
\hline & $2.5 \mathrm{mg}$ & $5 \mathrm{mg}$ & $10 \mathrm{mg}$ & $20 \mathrm{mg}$ & $50 \mathrm{mg}$ & Placebo & $2.5 \mathrm{mg}$ & $5 \mathrm{mg}$ & $10 \mathrm{mg}$ & Placebo & $10 \mathrm{mg}$ & $20 \mathrm{mg}$ & Placebo \\
\hline $\begin{array}{c}\text { Mean change from } \\
\text { baseline in FPG }(\mathrm{mg} / \mathrm{dl})\end{array}$ & -16 & -19 & -21 & -24 & -31 & -6 & -17.8 & -21.5 & -23.5 & -6.0 & -2.4 & -9.6 & 17.8 \\
\hline $\begin{array}{l}\text { Change from baseline } \\
\text { in PPG }\end{array}$ & $-9382^{a}$ & $-8478^{a}$ & $-10149^{a}$ & $-7053^{a}$ & $-10,093^{a}$ & $-3182^{a}$ & & & & & $-34.3^{\mathrm{b}}$ & $-41.9^{b}$ & $18.7^{\mathrm{b}}$ \\
\hline $\begin{array}{l}\text { Mean absolute change } \\
\text { from } \\
\text { baseline in HbA1c (\%) }\end{array}$ & -0.71 & -0.72 & -0.85 & -0.55 & -0.90 & -0.18 & -0.67 & -0.70 & -0.84 & -0.30 & -0.61 & -0.69 & 0.09 \\
\hline
\end{tabular}

AUC: Area Under the Curve; FPG: Fasting Plasma Glucose; HbA1c: Hemoglobin A1c; OAD: Oral Antidiabetic Drug; PPG: Postprandial Plasma Glucose. a Mean change in AUC $\left((\mathrm{mg} / \mathrm{dL})^{*} \mathrm{~min}\right)$, bPlasma glucose levels measured after $120 \mathrm{~min}$ during a $75 \mathrm{~g}$ oral glucose tolerance test [31].

Table 3: Effect of dapagliflozin on blood glucose parameters.

that dapagliflozin reduces the plasma glucose level in the same manner as of glipizide with lesser episodes of hypoglycemia. It also reduces the systolic as well as diastolic blood pressure in the type 2 diabetes mellitus patients. Consequently the patients treated with dapagliflozin experiences the weight loss while patients receiving the glipizide sustained weight gain.

Dapagliflozin has marked effect on blood glucose level. Some excellent investigations [3-30], in the treatment naive patients for 12 weeks, in patients on metformin monotherapy for 24 weeks and in poorly controlled patients receiving insulin and oral antidiabetic drug for 12 weeks shows that dapagliflozin has dose dependent effect on the PPG (Post prandial glucose) levels in poorly controlled patients while dose dependency is lesser in case of treatment-naïve patients. The above study clarifies that higher filtered load of glucose in poorly controlled patients in responsible for higher excretion of glucose from the kidney which results in the better HbA1c values [31] (T 2).

Some important recent research exertion represents the utility of the dapagliflozin in the type-2 diabetes mellitus (T2DM) patients. Dapagliflozin has been administered to the T2DM patients either alone [32] or in combination with metformin [25], insulin [29,33] ,sulfonylureas [26,27], or thiazolidinediones [34] and shown to improve the glycemic control. Furthermore, one significant research
[35] demonstrates the advantages of dapagliflozin over metformin, a standard conventional drug. The study illustrate that when dapagliflozin has been added to the metformin therapy in T2DM patients for 102 weeks, a marked reduction in Glycated Heamoglobin (HbAlc), Fasting Plasma Glucose (FPG) and weight has been observed without increasing the risk of hypoglycemia. This clinical trial showed that the treatment of dapagliflozin with metformin acts independently of $\beta$-cell function or insulin sensitivity, thereby suggested a different therapeutic approach to currently available conventional drugs. Additionally, European Medicine Agency makes dapagliflozin a first agent in the class of SGLT2 inhibitors. One recent research has portraying the effect of dapagliflozin on the Health Related Quality of Life (HRQOL) [36]. The study revealed that patients receiving dapagliflozin over 2 years had improved HRQOL to a significant level. Consequently, dapagliflozin showed no signs of carcinogenicity suggesting no indication of tumor progression or development as shown by one of the recent research work [37].

\section{Remigliflozin}

Remigliflozin is an O-glycoside SGLT2 inhibitor. It was developed as a consequential candidate for SGLT2 inhibition with better selectivity and pharmacokinetic profile [38]. 

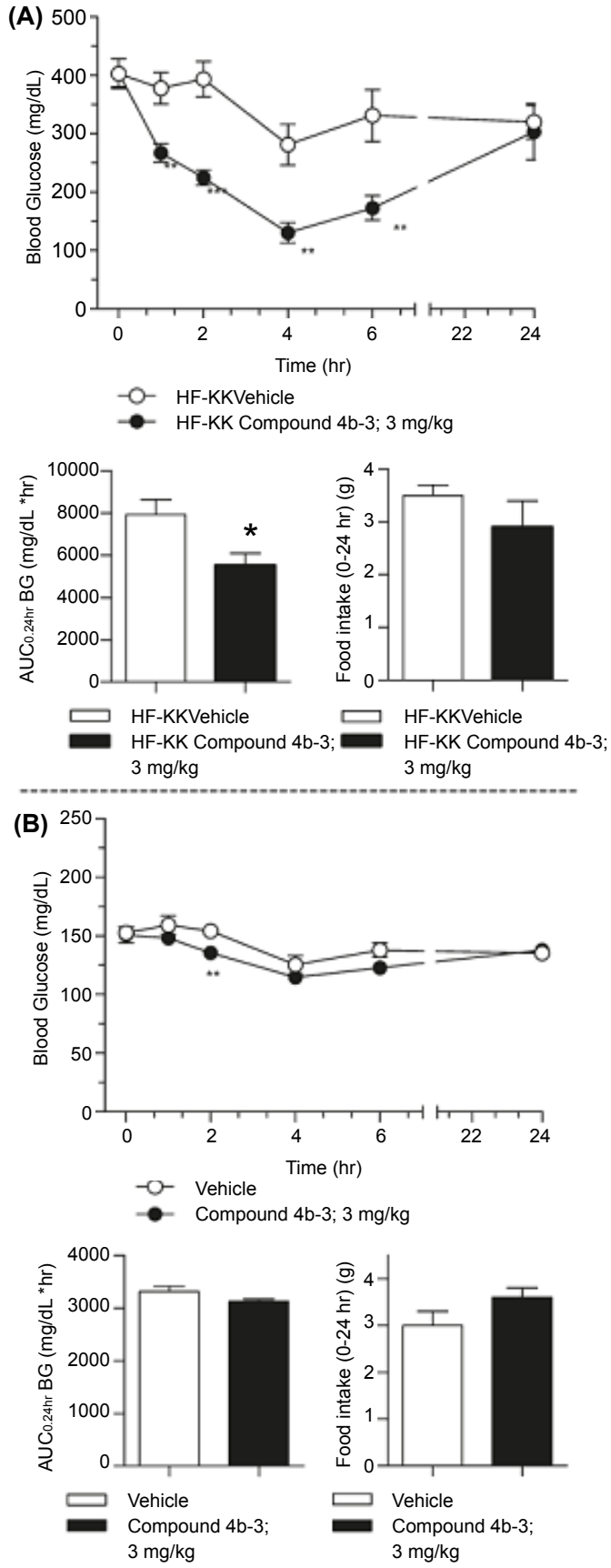

Figure 5: Effects of single oral dosing of Canagliflozin on blood glucose levels and food intake in high-fat diet fed KK (HF-KK) (A) and normal (B) mice.

Data are expressed as the mean SEM $(n=5):{ }^{*} P<0.05,{ }^{* *} P<0.01$ vs vehicle [41]. *Pb0.05, ${ }^{* *} \mathrm{Pb0} 0.01$ vs. vehicle group [20].

Its selectivity towards human SGLT2 was higher as compared to human SGLT1. (Ki values: 12.4 and $4520 \mathrm{nmol} / \mathrm{l}$ towards human SGLT2 and human SGLT1 respectively). While remigliflozin etabonate inhibit SGLT2 more potently in vivo as compared to the Phlorizin, Sergliflozin and T-1095. Remigliflozin is an O-glycoside which is susceptible to $\beta$-glucosidase [39]. Moreover, it causes reduction of blood glucose and body weight as well as the blood pressure in type2 diabetes mellitus patients [21].

\section{Canagliflozin}

Canagliflozin is another C-glucoside and has $~ 200$-fold selectivity for SGLT2 $\left(\mathrm{IC}_{50} 2.2 \mathrm{nM}\right)$ as compared to SGLT1 $\left(\mathrm{IC}_{50} 0.44 \mu \mathrm{M}\right)$ [40] (Table 3). One recent research has shown the potency and selectivity of Canagliflozin towards SGLT2 inhibition. There was noteworthy decrease in the blood glucose level receiving the Canagliflozin at 3mg/ $\mathrm{kg}$ without any alteration in the food intake in hyperglycemic highfat diet fed KK (HG-KK) mice (Figure 5). On the contrary there is only slight reduction in the blood glucose levels in normoglycemic mice. Consequently, it can be said that there will be less hypoglycemic episodes with Canagliflozin. Furthermore, Canagliflozin remarkably increases the urinary glucose excretion [41]. At this moment in time Canagliflozin is under Phase-III clinical trial.

Canalgliflozin is associated with higher incidences of genital mycotic infections in males and females as compared to the conventional dipeptidyl peptidases -IV (DDP-IV) inhibitor as reported in one of the study [42]. Furthermore, the infection of candida albicans Colony Forming Units (CFU) was significantly increased with the use of canalgliflozin [43]. Efficacy of canalgliflozin versus Glimepiride in type- 2 diabetes mellitus patients was evaluated. Glimepiride reduced the mean baseline HbAlc from 7.8-6.99\%, while canalgliflozin when given as monotherapy at a dose of $100 \mathrm{mg}$ reduced the baseline $\mathrm{HbAlc}$ from 7.8-6.98\% and when given in the dose of $300 \mathrm{mg}$ causes a reduction of $\mathrm{HbA} 1 \mathrm{c}$ from 7.8 to $6.87 \%$. Additionally, the fasting plasma glucose was reduced to a significant extent with the dose of canalgliflozin at $100 \mathrm{mg}(1.3 \mathrm{mmol} / \mathrm{l})$ and $300 \mathrm{mg}(1.52 \mathrm{mmol} / \mathrm{l})$ when compared to the conventional sulfonylureas i.e., Glimepiride (1.02 mmol/l) [44]. In one of the important study, patients received canalgliflozin for 6 to 12 months improves the model based measure of beta cell function in Phase 3 studies [45].

On the contrary, when canalgliflozin has been used in geriatric patients and in those with renal impairment, showed reduced efficacy and increased risk of adverse reactions like hypotension, renal impairment, hyperkalemia, hypoglycemia, genial mycotic infections, increased level of low density lipoproteins and hypersensitivity reactions [46] (Table 4 and 5).

\begin{tabular}{|c|c|c|c|c|}
\hline & \multicolumn{3}{|c|}{ IC50 (nM) } & \\
\hline Compound & hSGLT1 & hSGLT2 & GLUT1 & UGE (mg/day) \\
\hline Canagliflozin & 910 & 2.2 & $>10000$ & 3696 \\
\hline
\end{tabular}

Table 4: hSGLT1, hSGLT2, Facilitated Glucose Transporter 1 (GLUT1) Inhibitory Activity, and Rat Urinary Glucose Excretion (UGE) Data for Canagliflozin [41].

\begin{tabular}{|c|c|c|}
\hline Compound & Manufacturing Company & Development Phase \\
\hline T-1095 & Tanabe & Discontinued \\
\hline TS-033 & Taisho & Discontinued \\
\hline AVE2268 & Sanofi-Aventis & Discontinued \\
\hline YM-543 & Astellas/Kotobuki & Discontinued \\
\hline Remogliflozin & GlaxoSmithKline & Discontinued \\
\hline Sergliflozin & GlaxoSmithKline/Kissei & Discontinued \\
\hline Dapagliflozin & Bristol-Myers Squibb/AstraZeneca & Phase III \\
\hline Canagliflozin & JNJ/Mitsubishi Tanabe & Phase III \\
\hline BI 10773 & Boehringerlngelheim & Phase II \\
\hline BI 44847 & Boehringerlngelheim/Ajinomoto & Phase II \\
\hline R-7201 & Roche/Chugai & Phase II \\
\hline TS-071 & Taisho & Phase II \\
\hline LX4211 & Lexicon & Phase II \\
\hline
\end{tabular}

Table 5: Clinical progress of some important SGLT2 inhibitors for the treatment of type 2 diabetes mellitus [39]. 
Citation: Ahmed D, Sharma M, Kumar V, Pankajkumar Y, chandra S (2014) An Emerging Protagonist: Sodium Glucose Co-transporters (SGLTs) as a Burgeoning Target for the Treatment of Diabetes Mellitus. J Diabetes Metab 5: 358 doi:10.4172/2155-6156.1000358

Page 6 of 7

\section{Empagliflozin}

Empagliflozin is a novel, potent and selective SGLT-2 inhibitor. Some of the important studies demonstrated that empagliflozin enhances the urinary glucose excretion with concomitant reductions in the fasting and postprandial glucose levels and glycated hemoglobin (HbAlc) in Zukar Diabetic Fatty (ZDF) rats [47,48]. One important study [49] showed the significance of combinatorial therapy of empagliflozin with insulin in type-1 diabetes mellitus (T1DM) rats. The research work clearly revealed that addition of empagliflozin to insulin pre-treated rats causes prolonged reductions in hyperglycemia, without any episode of hypoglycemia. It was also disclosed in that research work that improved glycemic control can be achieved with lower doses of insulin if empagliflozin is added to the therapy.

As far as the safety and tolerability of empagliflozin is concerned, it is safe with no signs of urinary tract infections. The safety and tolerability of empagliflozin was further confirmed by one of the important study [50]. This research works illustrates that empagliflozin is well tolerated and risk of hypoglycemia is very low.

Additionally, a small decrease in the estimated Glomerular Filteration Rates (eGFR) was reported in the groups of patients treated with empagliflozin. Nevertheless, eGFR returned to normal levels within 3 weeks of the termination of treatment. This suggests that empagliflozin does not have any detrimental effect on kidney function. The trial investigations on empagliflozin show that when empagliflozin was added to the existing medications in stage 2 and stage 3 Chronic Kindey Diseases (CKD), there was no adverse event reported and $\mathrm{HbAlc}$ levels decreases to a significant level [51].

\section{Contemporary View and Prospective Advantages of the SGLT2 Inhibitors}

Many new SGLT2 inhibitors have been developed as result of modification in the prototype Phlorizin. After withdrawal of nonselective SGLT2 inhibitors viz. Phlorizin, T-1095 etc, newer SGLT2selective inhibitors such as sergliflozin, remogliflozin, AVE-2268 and YM-543 have also been taken off. Though new selective SGLT2 inhibitors curtail the adverse effects resulted from SGLT1 inhibition such as gastrointestinal disturbances which is associated with the nonselective SGLT2 inhibitors.

Sergliflozin and Dapagliflozin reduce the blood pressure probably by their osmotic diuretic and tuboglomerular reflex. As far as the Pharmacokinetic profile is concerned C-glycosides are longer acting as compared to O-glycosides. Consequently, C-glycosides suppress the postprandial hyperglycemia and fasting hyperglycemia more prominently than short acting O-glycosides. Controlling the postprandial hyperglycemia is vital for thwarting cardiovascular adverse effects [52].

The important gain from SGLT2 inhibitors is the co-transportation of the sodium as well as glucose which reduces the reabsorption of both the glucose and sodium which results in diuretic action of SGLT2 inhibitors. Another benefit of SGLT2 inhibitor is the reduction of blood glucose without any change in the body weight which is the adverse effect associated with most of the Oral Antidiabetic Drugs (OADs) such as sulfonylureas, insulin and Thiazolidinediones (TZDs).

\section{Limitations of the SGLT2 Inhibitors}

Although the mechanism of action of SGLT2 inhibitors may resides potential benefits in it, nevertheless they are associated with an assortment of precincts as well such as polyuria and polydipsia which results in hypovolemia particularly in the dehydrated patients. Urinary excretion of glucose also results in an increased risk of Urinary Tract Infections (UTIs) and genitourinary infections. Furthermore, most of the Oral Antidiabetic Drugs (OADs) either improve insulin resistance or insulin secretion whereas SGLT2 inhibitors are thought to increase the glycemic control through urinary excretion of the same, irrespective of how the glucose level increased. Consequently diminution of glucotoxicity might improve the insulin resistance as well as the insulin secretion.

\section{Conclusion}

Currently overabundances of therapies are available to target the diabetes mellitus. Nevertheless, targeting the glucose level remain on top priority in sizeable percentage of type 2 diabetes mellitus patients. Increased blood glucose level contributes to the succession and development of type 2 diabetes mellitus. Reducing the blood glucose level through increased urinary excretion of sugar put forward impending advantages of better glycemic control, minimum risk of hypoglycemia and sympathetic effect on the body weight. At present many companies are developing potential SGLT2 inhibitors with different selectivity, pharmacokinetic profiles, potency and efficacy. SGLT2 inhibitors are expected to improve the glycemic control, insulin resistance as well as the conservation of pancreatic $\beta$-cells. The insulin independent mechanism of action of SGLT2 inhibitors might provide better treatment for the type 2 diabetes mellitus patients. These are expected to provide better synergistic results when used as combinatorial therapy with other antidiabetic drugs despite predictable adverse effects for instance polyuria, urinogenital infections, and UTIs.

\section{References}

1. International Diabetes Federation (2009) Diabetes Atlas (4thedn) Internationa Diabetes Federation: Montreal, Canada, 2009.

2. Dwarakanathan A (2006) Diabetes update. J Insur Med 38: 20-30.

3. Mackenzie B, Loo DD, Panayotova-Heiermann M, Wright EM (1996) Biophysical characteristics of the pig kidney Na+/glucose cotransporter SGLT2 reveal a common mechanism for SGLT1 and SGLT2. J BiolChem 271: 32678 32683.

4. Moe OW, Berry CA, Rector FC (2000) The Kidney, In: Brenner BM, Rector FC (Eds.) ( $5^{\text {th }}$ edn), WB Saunders Co, Philadelphia, PA: 375-415.

5. Washburn WN (2009) Evolution of sodium glucose co-transporter 2 inhibitors as anti-diabetic agents. Expert OpinTher Pat 19: 1485-1499.

6. Kinne RK (1991) Selectivity and direction: plasma membranes in renal transport. Am J Physiol 260: F153-162.

7. Burckhardt G, Kinne RKH (1992) Transport proteins. Cotransporters and countertransporters. In: Seldin DW, Giebisch G (Eds), The kidney: physiology and pathophysiology, Raven, New York: 537-586.

8. Wright EM, Hirayama BA, Loo DF (2007) Active sugar transport in health and disease. J Intern Med 261: 32-43.

9. Morrison Al, Panayotova-Heiermann M, Feigl G, Schölermann B, Kinne RK (1991) Sequence comparison of the sodium-D-glucose cotransport systems in rabbit renal and intestinal epithelia. BiochimBiophysActa 1089: 121-123.

10. Kipp H, Kinne-Saffran E, Bevan C, Kinne RK (1997) Characteristics of renal $\mathrm{Na}(+)$-D-glucose cotransport in the skate (Raja erinacea) and shark (Squalusacanthias). Am J Physiol 273: R134-142.

11. Ehrenkranz JR, Lewis NG, Kahn CR, Roth J (2005) Phlorizin: a review. Diabetes Metab Res Rev 21: 31-38.

12. Rossetti L, Smith D, Shulman GI, Papachristou D, DeFronzo RA (1987) Correction of hyperglycemia with phlorizin normalizes tissue sensitivity to insulin in diabetic rats. J Clin Invest 79: 1510-1515.

13. Rossetti L, Giaccari A, DeFronzo RA (1990) Glucose toxicity. Diabetes Care 13: $610-630$ 
Citation: Ahmed D, Sharma M, Kumar V, Pankajkumar Y, chandra S (2014) An Emerging Protagonist: Sodium Glucose Co-transporters (SGLTs) as a Burgeoning Target for the Treatment of Diabetes Mellitus. J Diabetes Metab 5: 358 doi:10.4172/2155-6156.1000358

14. Kanai Y, Lee WS, You G, Brown D, Hediger MA (1994) The human kidney low affinity $\mathrm{Na}+$ /glucose cotransporter SGLT2. Delineation of the major renal reabsorptive mechanism for D-glucose. J Clin Invest 93: 397-404.

15. Panayotova-Heiermann M, Loo DD, Wright EM (1995) Kinetics of steadystate currents and charge movements associated with the rat $\mathrm{Na}+$ glucose cotransporter. J BiolChem 270: 27099-27105.

16. Isaji M (2007) Sodium-glucose cotransporter inhibitors for diabetes. CurrOpinlnvestig Drugs 8: 285-292.

17. Meng W, Ellsworth BA, Nirschl AA, McCann PJ, Patel M, et al. (2008) Discovery of dapagliflozin: a potent, selective renal sodium-dependent glucose cotransporter2 (SGLT2) inhibitor for the treatment of type 2 diabetes. J Med Chem 51: 1145-1149.

18. Oku A, Ueta K, Arakawa K, Ishihara T, Nawano M, et al. (1999) T-1095, an inhibitor of renal $\mathrm{Na}$ +-glucose cotransporters, may provide a novel approach to treating diabetes. Diabetes 48: 1794-1800.

19. Katsuno K, Fujimori Y, Takemura Y, Hiratochi M, Itoh F, et al. (2007) Sergliflozin, a novel selective inhibitor of low-affinity sodium glucose cotransporter (SGLT2), validates the critical role of SGLT2 in renal glucose reabsorption and modulates plasma glucose level. J PharmacolExpThr 320: 323-330.

20. Fujimori $Y$, Katsuno K, Ojima K, Nakashima I, Nakano S, et al. (2009) Sergliflozinetabonate, a selective SGLT2 inhibitor, improves glycemic control in streptozotocin-induced diabetic rats and Zucker fatty rats. Eur J of Pharmaco 609: 148-154.

21. Dobbins R, Kapur A, Kapitza C, O'Connor-Semmes R, Tao W, et al. (2009) Remogliflozinetabonate, a selective inhibitor of the sodium-glucose transporter 2 (SGLT2) reduces serum glucose in type 2 diabetes mellitus (T2DM) patients. Diabetes 58.

22. Hussey EK, Kapur A, O'Connor-Semmes R, Tao W, Poo J, et al. (2009) Safety, pharmacokinetics and pharmacodynamics of remogliflozinetabonate (SGLT2 inhibitor) and metformin when coadministered in type 2 diabetes mellitus (T2DM) patients. Diabetes 58

23. Hussey E, Clark RV, Amin DM (2007) Early clinical studies to assess the safety, tolerability, pharmacokinetics and pharmacodynamics of single doses of sergliflozin, a novel inhibitor or renal glucose reabsorption, in healthy volunteers and subjects with type 2 diabetes mellitus. Diabetes 56:A49.

24. Tahrani AA, Barnett AH (2010) Dapagliflozin: a sodium glucose cotransporter 2 inhibitor in development for type 2 diabetes. Diabetes Ther 1: 45-56.

25. Bailey CJ, Gross JL, Pieters A, Bastien A, List JF (2010) Effect of dapagliflozin in patients with type 2 diabetes who have inadequate glycaemic control with metformin: a randomised, double-blind, placebo-controlled trial. Lancet 375 : 2223-2233.

26. Strojek K, Yoon KH, Hruba V, Elze M, Langkilde AM, et al. (2011) Effect of dapagliflozin in patients with type 2 diabetes who have inadequate glycaemic control with glimepiride: a randomized, 24-week, double-blind, placebocontrolled trial. Diabetes ObesMetab 13: 928-938.

27. Nauck, M. A. et al. Dapagliflozin versus glipizide as add-on therapy in patients with type 2 diabetes who have inadequate glycemic control with metformin. Diabetes Care 34, 2015-2022 (2011)

28. List JF, Woo V, Morales E, Tang W, Fiedorek FT (2009) Sodium-glucose cotransport inhibition with dapagliflozin in type 2 diabetes. Diabetes Care 32 : 650-657.

29. Wilding JP, Norwood P, T'joen C, Bastien A, List JF, et al. (2009) A study of dapagliflozin in patients with type 2 diabetes receiving high doses of insulin plus insulin sensitizers: applicability of a novel insulin-independent treatment. Diabetes Care 32: 1656-1662.

30. Bailey CJ, Gross JL, Bastone L (2009) Dapagliflozin as an add-on to metformin lowers hyperglycaemia in type 2 diabetes patients inadequately controlled with metformin alone. Diabetologia 52: S76.

31. List JF, Whaley JM (2011) Glucose dynamics and mechanistic implications of SGLT2 inhibitors in animals and humans. Kidney Int Suppl : S20-27.

32. Ferrannini E, Ramos SJ, Salsali A, Tang W, List JF (2010) Dapagliflozinmonotherapy in type 2 diabetic patients with inadequate glycemic control by diet and exercise: a randomized, double-blind, placebo-controlled, phase 3 trial. Diabetes Care 33: 2217-2224.

33. Wilding JP, Woo V, Soler NG, Pahor A, Sugg J, et al. (2012) Long-term efficacy of dapagliflozin in patients with type 2 diabetes mellitus receiving high doses of insulin: a randomized trial. Ann Intern Med 156:405-415.
34. Rosenstock J, Vico M, Wei L, Salsali A, List JF (2012) Effects of dapagliflozin an SGLT2 inhibitor, on $\mathrm{HbA}(1 \mathrm{c})$, body weight, and hypoglycemia risk in patients with type 2 diabetes inadequately controlled on pioglitazone monotherapy Diabetes Care 35: 1473-1478.

35. Clifford J Bailey, Jorge L Gross, DelphineHennicken, Nayyarlqbal , Traci A Mansfield, et al. (2013) Dapagliflozin add-on to metformin in type 2 diabetes inadequately controlled with metformin: a randomized, double-blind, placebocontrolled 102-week trial. BMC Medicine 11:43.

36. Grandy S, Langkilde AM, Sugg JE, Parikh S, Sjöström CD (2014) Healthrelated quality of life (EQ-5D) among type 2 diabetes mellitus patients treated with dapagliflozin over 2 years. Int J ClinPract 68: 486-494.

37. Reilly TP, Graziano MJ, Janovitz EB, Dorr TE, Fairchild C, et al. (2013) Carcinogenicity Risk Assessment Supports the Chronic Safety of Dapagliozin an Inhibitor of Sodium- Glucose Co-Transporter 2, in the Treatment of Type 2 Diabetes Mellitus. Diabetes Ther. [Epub ahead of print].

38. Fujimori Y, Katsuno K, Nakashima I, Ishikawa-Takemura $\mathrm{Y}$, Fujikura $\mathrm{H}$, et al. (2008) Remogliflozinetabonate, in a novel category of selective low-affinity sodium glucose cotransporter (SGLT2) inhibitors, exhibits antidiabetic efficacy in rodent models. J Pharmacol ExpTher 327: 268-276.

39. Isaji M (2011) SGLT2 inhibitors: molecular design and potential differences in effect. Kidney IntSuppl : S14-19.

40. Liang Y, Arakawa K, Martin T, Du FY, Xu JZ, et al. (2009) JNJ-28431754/TA7284 , an SGLT inhibitor, lowers blood glucose and reduces body weight in obese and type 2 diabetic animal models. Diabetes 58: A143.

41. Nomura S1, Sakamaki S, Hongu M, Kawanishi E, Koga Y, et al. (2010) Discovery of Canagliflozin, a Novel C-Glucoside with Thiophene Ring, as Sodium-Dependent Glucose Cotransporter 2 Inhibitor for the Treatment of Type 2 Diabetes Mellitus. J Med Chem 53: 6355-6360.

42. Forst T, Guthrie R, Goldenberg R, Yee J, Vijapurkar U, et al. (2014) Efficacy and safety of canagliflozin over 52 weeks in patients with type 2 diabetes on background metformin and pioglitazone. Diabetes ObesMetab.

43. Suzuki M, Hiramatsu M, Fukazawa M, Matsumoto M, Honda K, et al. (2014) Effect of SGLT2 inhibitors in a murine model of urinary tract infection with Candida albicans. Diabetes ObesMetab

44. Davis SN (2014) Canagliflozin versus glimepiride treatment in patients with type 2 diabetes inadequately controlled with metformin (CANTATA-SU trial). Expert Rev ClinPharmacol 7: 21-23.

45. Polidori D, Mari A, Ferrannini E (2014) Canagliflozin, a sodium glucose cotransporter 2 inhibitor, improves model-based indices of beta cell function in patients with type 2 diabetes. Diabetologia .

46. Toderika Y, Ferguson N (2014) Canagliflozin: a new class of antidiabetic agent targeting the sodium-glucose cotransporter. Cardiol Rev 22: 97-104.

47. Thomas L, Grempler R, Eckhardt M, Himmelsbach F, Sauer A, et al. (2012) Long-term treatment with empagliflozin, a novel, potent and selective SGLT-2 inhibitor, improves glycaemic control and features of metabolic syndrome in diabetic rats. Diabetes ObesMetab 14: 94-96.

48. Grempler R, Thomas L, Eckhardt M, Himmelsbach F, Sauer A, et al. (2012) Empagliflozin, a novel selective sodium glucose cotransporter-2 (SGLT2) inhibitor: characterisation and comparison with other SGLT-2 inhibitors. Diabetes ObesMetab 14: 83-90.

49. Luippold G, Klein T, Mark M, Grempler R (2012) Empagliflozin, a novel potent and selective SGLT-2 inhibitor, improves glycaemic control alone and in combination with insulin in streptozotocin-induced diabetic rats, a model of type 1 diabetes mellitus. Diabetes, Obesity and Metabolism 14: 601-607.

50. Heise T, Seewaldt-Becker E, Macha S, Hantel S, Pinnetti S, et al. (2013) Safety, tolerability, pharmacokinetics and pharmacodynamics following 4 weeks' treatment with empagliflozin once daily in patients with type 2 diabetes. Diabetes, Obesity and Metabolism 15: 613-621.

51. Barnett AH (2014) Efficacy and safety of empagliflozin added to existing antidiabetes treatment in patients with type 2 diabetes and chronic kidney disease: a randomised, double-blind, placebo-controlled trial. Lancet Diabetes Endocrinol13: S2213-8587.

52. Leiter LA, Ceriello A, Davidson JA, Hanefeld M, Monnier L, et al. (2005) Postprandial glucose regulation: new data and new implications. ClinTher 27 Suppl B: S42-56. 